\title{
WIND LOADING ON SOLAR PANELS
}

\author{
Ana Camelia SAUCA, ${ }^{1}$ Tudor MILCHIȘ, ${ }^{2}$ Ferdinánd-Zsongor GOBESZ ${ }^{3}$ \\ Technical University of Cluj-Napoca, Faculty of Civil Engineering, Cluj-Napoca, Romania \\ ${ }^{1}$ camelianna@yahoo.com \\ ${ }^{2}$ tudor.milchis@mecon.utcluj.ro \\ ${ }^{3}$ go@mecon.utcluj.ro
}

\begin{abstract}
A fully 3D numerical analysis of turbulent flow over a cluster of solar photovoltaic (PV) panels was performed in order to assess the total drag and lift forces, comparing the results with the values from the guidelines of the national standard. A Reynolds-Averaged Navier-Stokes (RANS) model was used in the numerical simulations, considering two acting directions of the wind along the length of the array ( 0 degree - front, and 180 degrees - reverse direction).
\end{abstract}

Keywords: wind load, drag and lift forces, solar photovoltaic panel (PV), Computational Fluid Dynamics (CFD), RANS.

\section{Introduction}

The harnessing of solar energy is usually done by using clusters of photovoltaic (PV) panels. The dimensions of these PV panel arrays are determined by the capacity of each panel and by the required amount of energy output. For their structural dimensioning the acting loads should be known. The total drag and lift forces have different values depending on the angle of the panel to the ground surface.

In the past years many researchers have carried out extensive studies of wind loads on PV panels. In some papers only one isolated panel was investigated, but with a large number of hypothesis regarding the wind direction or the angle values for the resultant of wind drag and lift. Such an extensive numerical study was done in [1] considering wind forces with different angles (range of values from $0^{\circ}$ to $90^{\circ}$ ) with $30^{\circ}$ inclination angle to the terrain surface (horizontal line). A scaled wind tunnel testing and a numerical simulation was performed by Ogedengbe et al. in [2] for a standalone PV module considering a wide range of wind flow directions from $0^{\circ}$ to $180^{\circ}$. In $[3,4,5]$ other results of standalone PV panels subjected to wind forces are presented.
Numerical studies and scaled wind tunnel testing on arrays of PV panels were also done by some researchers [6, 7, 8, 9]. with similar results. These panel structures appear to be simple only from the point of view of their geometrical shape. The flow of a fluid around them is turbulent, so accurate assessment of the wind induced forces is not easy. There are many parameters that influence the values of the drag forces (ground clearance, the inclination and size of the panels etc.); the most important one is the wind direction. With so many parameters that can change the entire structure's response to the wind load, one might consider it difficult to design and realize a structure in the middle of an empty field on which high wind speeds and gusts can occur. Thus, the design code overrates the total drag forces for this type of structure, for safety reasons. That is why not many structures have col-lapsed due to local gales.

The values for total drag forces and normal forces in the case of PV panel structures are not fully detailed in current Romanian design codes. Values of the drag coefficients in the case of wind loads can be found both in Eurocode 1 (SR EN 1991-1-4) and in the national standard (CR-1-1-42012), but solely for standalone panels subjected 
to the wind's action. In this paper two structures were analysed in order to evaluate the drag forces generated by wind pressure on their panels. These structures are more complex considering their response to the wind's action, so, instead of a full structural analysis the goal was set only to evaluate the drag and lift forces on the panels.

The geometry of the structures led us to a very high Reynolds number (in the order of 106), thus a turbulent flow model had to be used.

Wind load parameters for bluff bodies are the main interest in designing the structure for large billboards. Vortexes that appear in the wake of bluff body turbulence are defined by a high Reynolds value which reflects the flow state of a fluid around an obstacle. The geometrical particularities of a bluff body also influence the total drag or pressure coefficients, even if they are small in dimensions, so a full 3D numerical model is imperative whenever possible regarding the computational capabilities.

Starting from the solar intensity map of Romania, shown in Figure 1., the most suitable sites for placing solar farms made of PV panels can be chosen. While the south part is used mostly for agriculture, our area of interest is in the centre, where the relief is hillier, thus, the wind velocities are higher than on the flat areas in the southern part of the country.

Solar photovoltaic panel arrays in most cases are made from rectangular panels mounted on steel supports, having an inclination angle in order to be oriented towards the sun (Figure 2.). There are also more advanced models that follow the sun's path over the sky, the geometrical shape of these PVs is usually a curved one.

\section{Numerical model}

Two sets of PV panel arrays were considered, first a structure with four parallel panels (case A), and then another structure with seven parallel panels (case B). In both cases, the panels were composed from 24 smaller flat PV elements, with a $2 \mathrm{~cm}$ gap between them. Thus, the length of one panel resulted almost $10 \mathrm{~m}$ and the width over $3 \mathrm{~m}$ (Figure 3.). These panels were considered to be positioned over the ground with a 25 degree angle inclination, at $5 \mathrm{~m}$ from each other (Figure 4.).

In order to obtain accurate results considering turbulent air flow, a $52 \times 130 \times 10 \mathrm{~m}$ volume domain was modelled in Ansvs for the numerical simula-

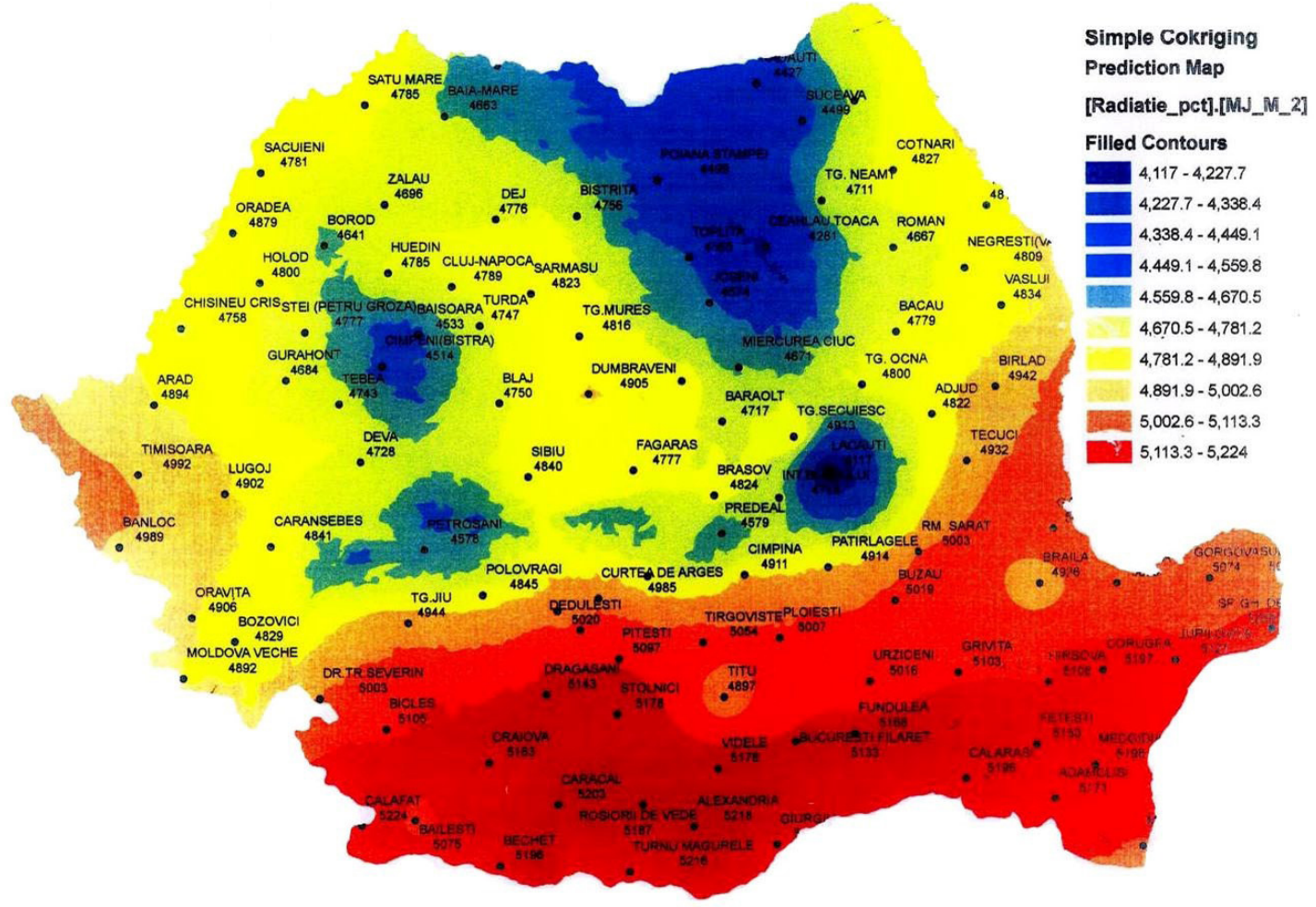

Figure 1. The solar intensity map of Romania [10] 
tions (although, for case A a smaller domain could have been used), as shown in Figure 5.

The required mesh for the convergence of the model needed a high number of finite elements, so a structured mesh was used (applying the cutcell method). The smallest element had edges of $5 \mathrm{E}-3 \mathrm{~m}$, with the first layer height $1 \mathrm{E}-3 \mathrm{~m}$ and a grow rate of 1.2. In the end, the defined mesh domain had $8.7 \mathrm{E}+6$ nodes and $7.5 \mathrm{E}+6$ elements overall in case B, considerably more than in case A. Figure 6. shows the variation of the mesh density near the panels.

The boundary conditions of the domain are illustrated in Figure 7. There was a modification for case A, where the top and the lateral edges of the fluid domain were considered as wall conditions (meaning no slip and no penetration). The

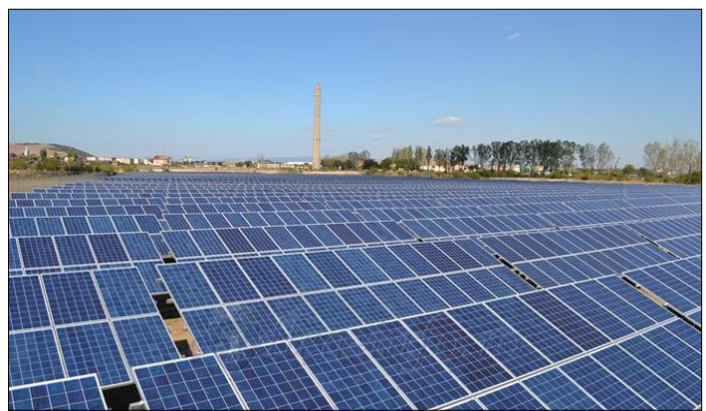

Figure 2. Solar photovoltaic panels arrays [11]

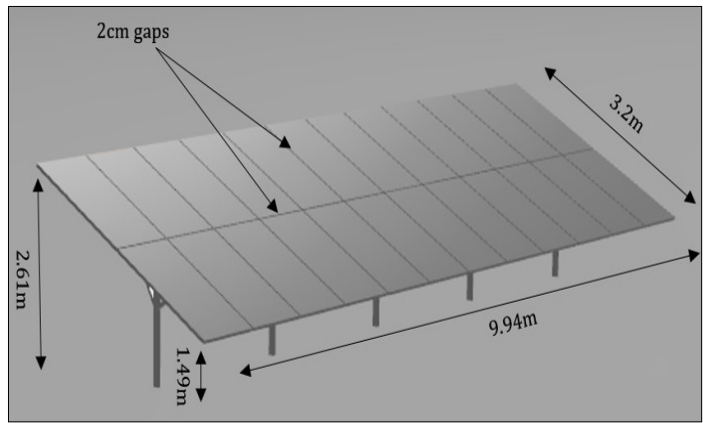

Figure 3. The geometry of a panel (composed from 24 flat PV elements) differences between these two approaches were irrelevant in the final results, so we can say, if a sufficient large domain is used, then both conditions are accurate.

The mathematical model used to solve the RANS equations was a $\mathrm{k}-\varepsilon$ turbulence model with enhanced wall treatment. In both cases only two hypotheses of wind directions angles $\left(0^{\circ}\right.$ and $\left.180^{\circ}\right)$ have been considered (as worst case scenario). Thus, the numerical studies were carried out for four hypotheses, further marked as A-front and A-back (case A), B-front and B-back (case B), according to the direction of the wind.

In both cases (case A with four panels and case B with seven panels), the fluid domain settings were the same, the observed fluid flow and the turbulence intensity were similar, only the resulted loading forces had different numerical values

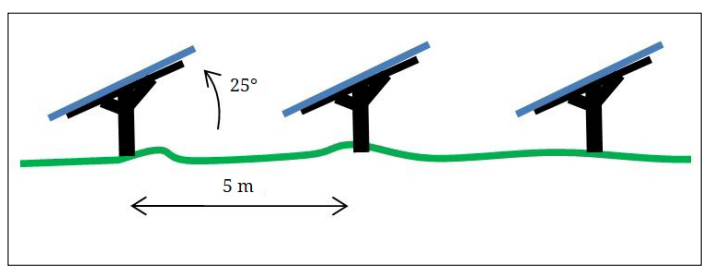

Figure 4. Setting of the panels in an array (row)

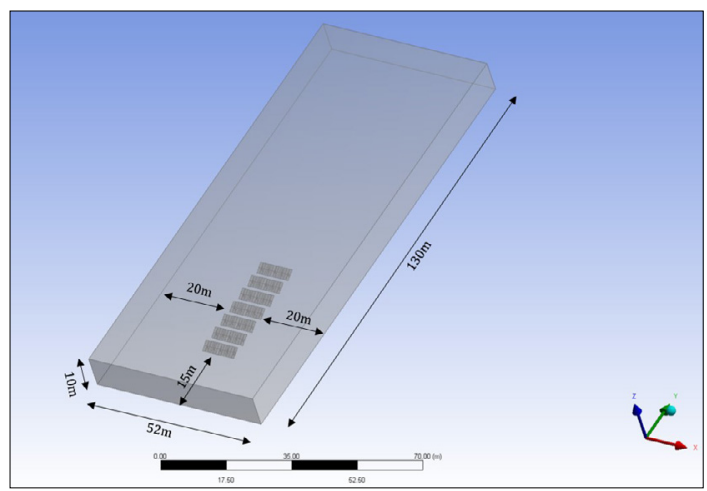

Figure 5. The numerical modelled domain (case B)

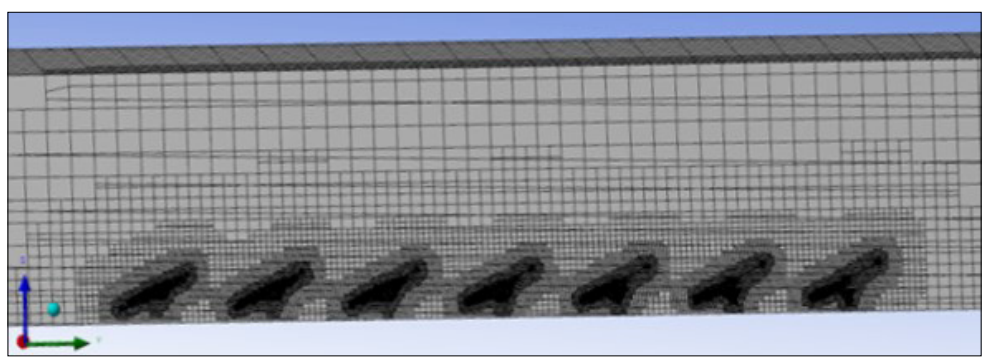

Figure 6. Mesh refinement near the walls boundary conditions (case B) 


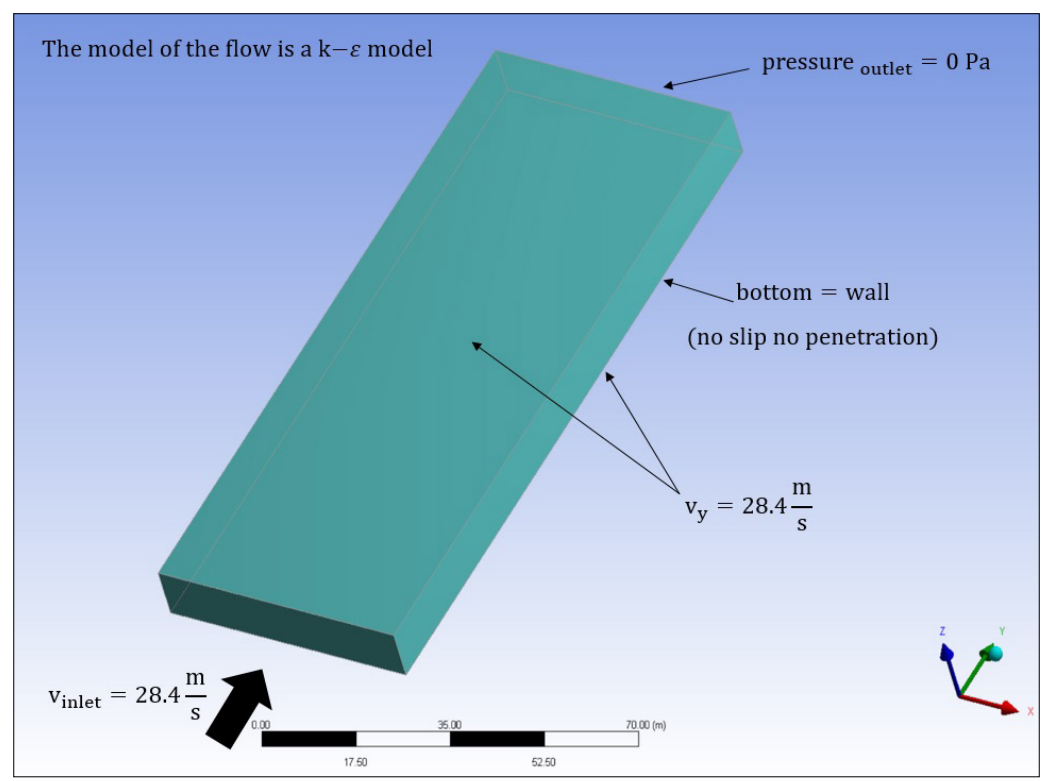

Figure 7. Boundary conditions of the fluid domain

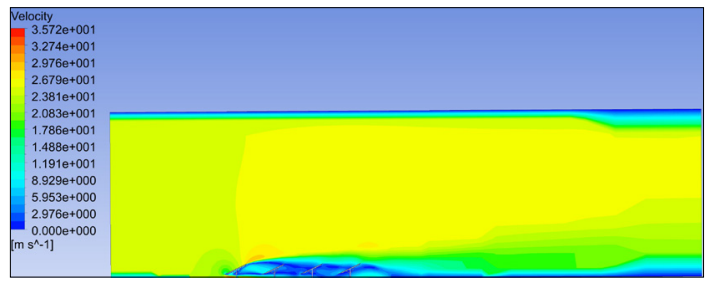

Figure 8. The wind velocity distribution in case A-front

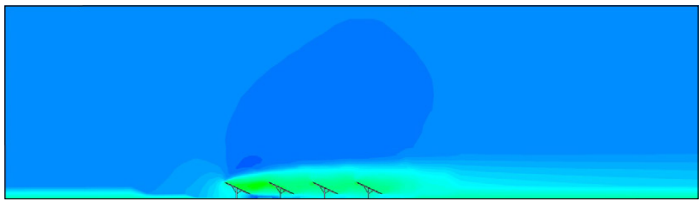

Figure 9. The wind velocity distribution in case A-back

Table 1. Drag and lift forces [N], case A-front

\begin{tabular}{|l|l|l|}
\hline \multicolumn{1}{|c|}{ Panel } & Drag (Y axis) & Lift (Z axis) \\
\hline P1 (windward) & 1539.3113 & -2887.2343 \\
\hline P2 & 1529.2392 & -2907.2607 \\
\hline P3 & 607.91867 & -949.07348 \\
\hline P4 (leeward) & 4422.9963 & -8837.388 \\
\hline
\end{tabular}

Table 2. Drag and lift forces [N], case A-backt

\begin{tabular}{|l|l|l|}
\hline \multicolumn{1}{|c|}{ Panel } & Drag (Y axis) & Lift (Z axis) \\
\hline P1 (leeward) & 2885.4727 & 5840.8222 \\
\hline P2 & 2276.3627 & 4602.1176 \\
\hline P3 & 607.93947 & 1147.551 \\
\hline P4 (windward) & 7325.4916 & 14972.468 \\
\hline
\end{tabular}

\subsection{Case A results}

The velocity distribution in a sectional plane through the middle of the domain, parallel with the longitudinal axis ( $\mathrm{Y}$ in our case), is shown in Figure 8. (case A-front) and Figure 9. (case A-back). The wind direction is always from the left side of the figure, to the right side of the figure. The total drag and lift forces, in case A-front and case A-back are synthesized in Table 1 . and Table 2.

\subsection{Case $B$ results}

The velocity distribution in a sectional plane through the middle of the domain, parallel with the longitudinal axis ( $\mathrm{Y}$ in our case), is shown in Figure 10. (case B-front) and Figure 11. (case B-back). The wind direction is always from the left side of the figure to the right side of the figure. The total drag and lift forces, in case B-front and case B-back are synthesized in Table 3. and Table 4 . The pressure distribution for case B-front is in Figure 12.

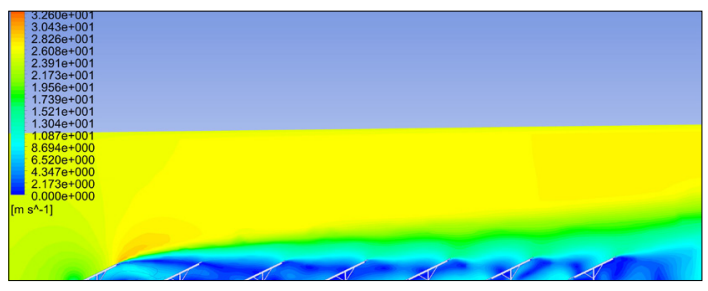

Figure 10. The wind velocity distribution in case B-front 


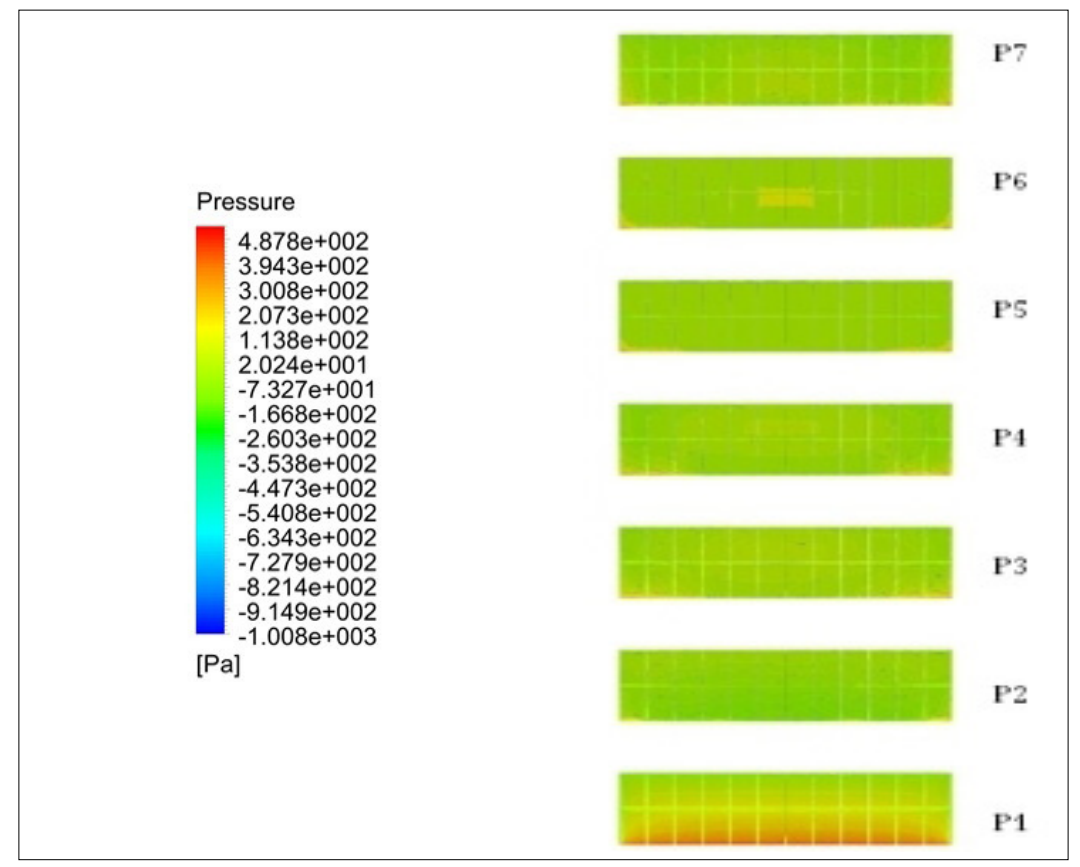

Figure 12. Pressure distribution on panels (case B-front).

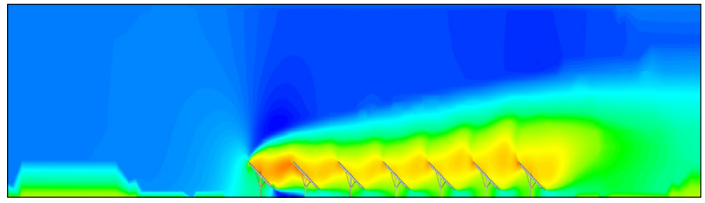

Figure 11. The wind velocity distribution in case B-back

Table 3. Drag and lift forces [N], case B-front

\begin{tabular}{|l|l|l|}
\hline \multicolumn{1}{|c|}{ Panel } & Drag (Y axis) & Lift (Z axis) \\
\hline P1 (windward) & 4613.7123 & -9182.1861 \\
\hline P2 & 583.24925 & -1065.778 \\
\hline P3 & 1330.112 & -2601.6572 \\
\hline P4 & 1172.4369 & -2251.5358 \\
\hline P5 & 1572.6932 & -3079.4485 \\
\hline P6 & 1841.3657 & -3654.8858 \\
\hline P7 (leeward) & 1934.8247 & -3850.5414 \\
\hline
\end{tabular}

Table 4. Drag and lift forces [N], case B-back

\begin{tabular}{|l|l|l|}
\hline \multicolumn{1}{|c|}{ Panel } & Drag (Y axis) & Lift (Z axis) \\
\hline P1 (leeward) & 2949.8167 & 5949.4786 \\
\hline P2 & 2505.5557 & 5062.3157 \\
\hline P3 & 2276.3973 & 4498.6831 \\
\hline P4 & 2194.8544 & 4348.1134 \\
\hline P5 & 2104.1257 & 4257.0653 \\
\hline P6 & 316.37399 & 613.9565 \\
\hline P7 (windward) & 7311.7861 & 15219.223 \\
\hline
\end{tabular}

\section{Conclusions}

During this study, the wind load was computed through numerical (CFD) simulation applied on two configurations of PV panel arrays, considering front and backward wind directions. In order to compare the numerical results with the values from the design codes, a manual calculation was performed according to CR-1-1-4-2012:

- the reference pressure of the wind, depending on the place of the structures is $q_{b}=0.5 \mathrm{kN} / \mathrm{m}^{2}$, from this value the wind velocity can be approximated as $v \approx 28.4 \mathrm{~m} / \mathrm{s}$ (the same value as in the numerical simulation);

- the total drag force in the direction of the wind action, considering pressure on the panels, was evaluated at $\mathrm{F}_{\mathrm{w}} \mathrm{ny}=10598 \mathrm{~N}(10.6 \mathrm{kN})$;

- the total drag force in the direction of the wind action, considering suction on the pan-els, was evaluated at $\mathrm{F}_{\mathrm{w}}{ }^{\mathrm{sz}}=-16957 \mathrm{~N}(17.0 \mathrm{kN})$.

Comparing these results to the values obtained through CFD simulation, it is obvious that the national code overestimates the total drag and lift force, mostly due to the fact that it considers a standalone PV panel. A standalone PV panel takes the whole force of the wind by itself.

The differences between the manual computed values and those obtained through numerical simulation are around $31 \%$ for the drag force and over $10 \%$ for the lift force. 


\section{References}

[1] Agarwal A., Irtaza H., Zameel A.: Numerical study of lift and drag coefficients on a ground-mounted photovoltaic solar panel. Matererials Today: Proceedings 4/9. (2017) 9822-9827. https://doi.org/10.1016/j.matpr.2017.06.274

[2] Abiola-Ogedengbe A., Hangan H., Siddiqui K.: Experimental investigation of wind effects on a standalone photovoltaic (PV) module. Renew. Energy, 78. (2015) 657-665. https://doi.org/10.1016/j.renene.2015.01.037

[3] Jubayer C. M., Hangan H.: Numerical simulation of wind effects on a standalone ground mounted Photovoltaic (PV) system. Journal of Wind Engineering and Industrial Aerodynamics 134. (2014) 56-64. https://doi.org/10.1016/j.jweia.2014.08.008

[4] Mier-Torrecilla M., Herrera E., Doblaré M.: $\mathrm{Nu}$ merical calculation of wind loads over solar collectors. Energy Procedia, 49. (2013) 163-173. https://doi.org/10.1016/j.egypro.2014.03.018

[5] Reina G. P., De Stefano G.: Computational evaluation of wind loads on sun-tracking ground-mounted photovoltaic panel arrays. Journal of Wind Engineering and Industrial Aerodynamics, 170. (2017) 283-293.

https://doi.org/10.1016/j.jweia.2017.09.002
[6] Jubayer C. M., Hangan H.: A numerical approach to the investigation of wind loading on an array of ground mounted solar photovoltaic (PV) panels. Journal of Wind Engineering and Industrial Aerodynamics, 153. (2016) 60-70. https://doi.org/10.1016/j.jweia.2016.03.009

[7] Warsido W. P., Bitsuamlak G. T., Barata J., Gan Chowdhury A.: Influence of spacing parameters on the wind loading of solar array. Journal of Fluids and Structures, 48. (2014) 295-315. https://doi.org/10.1016/j.jfluidstructs.2014.03.005

[8] Cain J. H., Banks D.: Wind Loads on Utility Scale Solar PV Power Plants. 2015 SEAOC Convention Proceedings. 1-8.

[9] Alluri S. K. R., Shit T., Gujjula D., Phani Kumar S. V. S., Ramana Murthy M. V.: Feasibility study on fixed platforms for offshore wind turbine in India. Journal of Structural Engineering (India), 41/1. (2014) 1248-1256.

https://doi.org/10.3850/978-981-07-8012-8_262

[10] Energy Street: Global solar radiations (letöltve 2018. november 20.)

http://energystreet.ro/en/photovoltaic/romania-solar-map

[11] Kelvin PDC: Panouri solare fotovoltaice (letöltve 2018. nov. 20.)

http://pompedecaldura2005.ro/echipamente/panouri-solare-fotovoltaic/\#.W_azih8lGkB 